\title{
DA PELEJA DE CEGO ADERALDO COM ZÉ PRETINHO DO TUCUM À PELEJA DE ADERALDO FILHO DO CEGO COM ALEXANDRE O NETO DE ZE PRETINHO*
}

DE LA PELEJA DE CEGO ADERALDO COM ZÉ PRETINHO DO TUCUM A LA PELEJA DE ADERALDO FILHO DO CEGO COM ALEXANDRE O NETO DE ZE PRETINHO

FROM THE FIGHT OF BLIND ADERALDO WITH ZÉ PRETINHO FROM TUCUM TO THE FIGHT OF ADERALDO SON OF THE BLIND WITH ALEXANDER THE NETO, SON OF ZE PRETINHO

\section{CARLOS NOGUEIRA**, JOHN REX AMUZU GADZEKPO***}

\section{RESUMO}

Neste artigo analisamos uma das mais célebres pelejas brasileiras, a Peleja de cego Aderaldo com Zé Pretinho do Tucum (1916), de Firmino Teixeira do Amaral, e estudamos também a Peleja de Aderaldo filho do cego, com Alexandre o Neto de Zé Pretinho, de João A. de Barros. Com esta abordagem queremos mostrar que na peleja brasileira (e, em particular, na peleja de cordel) e no mundo que ela representa a lei do mais forte é muitas vezes subvertida. Contra os mais fortes levantam-se os mais fracos, as mulheres, os escravos e outros oprimidos como os cegos, que, pela destreza poética e pela força anímica e intelectual, conseguem aproximar-se daqueles que se consideram e dizem mais fortes, e à frente deles desmentem e desfazem tabus, preconceitos e fobias.

Palavras-chave: Peleja, literatura de cordel, Brasil, cegos, negros.

\section{RESUMEN}

En este artículo analizamos una de las más célebres pelejas (disputas) brasileñas, la $P e-$ leja de cego Aderaldo com Zé Pretinho do Tucum (1916), de Firmino Teixeira do Amaral, y también estudiamos la Peleja de Aderaldo Filho do cego, com Alexandre o Neto de Zé

* Este estudo foi realizado no contexto do projeto "Contemporary Poetry and Politics: Research on Contemporary Relations between Cultural Production and Sociopolitical Context" (POEPOLIT, FFI2016-77584-P, 2016-2019, Ministerio de Economía y Competitividad del Gobierno de España).

** Doutor. Cátedra Internacional José Saramago, Facultad de Filoloxía e Tradución, Universidade de Vigo. Vigo, España. Correo: carlosnogueira@uvigo.es

*** Doutor. Ghana Institute of Languages. Correo: amuzu22@yahoo.com 
Pretinho, de João A. de Barros. Con esta aproximación queremos mostrar que en la peleja brasileña (y, en particular, en la peleja de cordel) y en el mundo que ella representa la ley del más fuerte resulta subvertida a menudo. Contra los más fuertes se levantan los más débiles, las mujeres, los esclavos y otros seres oprimidos, como los ciegos, quienes, mediante su destreza poética y su fuerza anímica e intelectual, consiguen aproximarse a aquellos que se consideran y que dicen ser más fuertes, y ante ellos desmienten y destruyen tabúes, prejuicios y fobias.

Palabras clave: Peleja, literatura de cordel, Brasil, ciegos, negros.

Recibido: 03.07.17. Aceptado: 23.10.17.

\begin{abstract}
In this article we analyze one of the most famous Brazilian fights, The fight of blind Aderaldo with Zé Pretinho do Tucum (1916), by Firmino Teixeira do Amaral, and we also discuss The fight of Aderaldo son of the blind with Alexander the Neto, son of Zé Pretinho, by João A. de Barros. With this approach we want to show that in the Brazilian fight (and, in particular, the fight in cordel literature) and in the world that it represents, the law that the strongest prevails is often subverted. Against the strongest, the weakest, women, slaves, and other oppressed people like the blind, by their poetic dexterity and their intellectual and mental strength, are able to defeat those who consider and proclaim themselves stronger, and in front of them they deny and undo taboos, prejudices and phobias.
\end{abstract}

Keywords: Fighting, cordel literature, Brazil, blind, black.

\title{
INTRODUÇÃO
}

PELEJA BRASILEIRA é um poema oral essencialmente dialógico em que
intervêm duas vozes individuais que se cruzam numa alternância
de forças psicológicas, intelectuais e criativas. Mas a peleja é tam- 
poética e retórica surpreendem o ouvinte e/ou o leitor pela complexidade e inventividade, não há limites temáticos. Tudo, desde o poder social e individual, a religião, o género e a masculinidade, a raça e a cor da pele, é objeto de tratamento.

A expressão "literatura de cordel" refere-se a uma das "persistentes manifestações da cultura popular brasileira" (Nogueira, 2014, p. 37), também nomeada pelos termos "folhetos", "folhetos de feira", "cordéis". Na génese desta literatura está a produção europeia de livrinhos populares conhecida, em Portugal, como "literatura de cordel" pelo menos desde 6 de junho de 1865, data da publicação, no Jornal do Comércio, do artigo "Literatura de cordel", de Teófilo Braga, e que constitui, nas palavras do autor em 1881, "a primeira tentativa para este trabalho" (Nogueira, 2004, p. 62). Diz-se de "cordel" porque os folhetos que a constituíam e constituem, no Brasil, "eram pendurados, para exposição e venda, em cordéis distendidos entre dois suportes, presos por alfinetes, pregos ou molas de roupa" (Nogueira, 2004, p. 7), e também porque quem vendia esses objetos impressos os colocava à cinta e também os podia exibir "a cavalo num barbante" (Nogueira, 2004, p. 8).

Esta literatura, que chegava ao Brasil desde Portugal, começa a ser produzida também em terras brasileiras na primeira metade e principalmente em finais do século XIX, com a chegada das tipografia ao interior do país. A literatura de cordel adquiriu uma identidade muito própria no Nordeste brasileiro, tanto no conteúdo como na linguagem, consubstanciada em folhetos, com cerca de 11 por 16 centímetros, de 8, 16, 32 e 48 páginas, "e sempre em verso, enquanto que na tradição europeia havia igualmente textos dramáticos e em prosa" (Nogueira, 2014, p. 37).

\section{CEGO CONTRA NEGRO}

Uma das obras mais vezes reeditada da literatura de cordel, a Peleja de cego Aderaldo com Zé Pretinho do Tucum (1916), de Firmino Teixeira do Amaral (1896-1926), opõe dois tipos geralmente considerados subalternos. Zé Pretinho é negro, o Cego Aderaldo é cego, como os próprios nomes sugerem. É conhecido o desdém geral em que os cegos são tidos no meio da cantoria e do cordel, e o estigma de ser negro neste contexto não é menos do conhecimento geral. Neste encontro, quem está em posição superior é Zé Pretinho. Em primeiro lugar, a peleja ocorre em Varzinha, a sua cidade, onde ele tem fama de grande cantador, facto reconhecido pelo próprio rival 
cego, a quem o autor entrega a voz poética da parte narrativa: "Apreciem meus leitores/ uma forte discussão/ que tive com Zé Pretinho/ um cantador do sertão/ o qual no tanger do verso/ vencia qualquer questão" (Amaral, 2004, p. 1). O próprio dono da casa onde vai acontecer a cantoria confirma a força e cabedal do cantador do sertão, e com isso procura menosprezar e amedrontar o cego: "Zé Preto pelo comum/ dá em dez ou doze cegos/ quanto mais sendo um" (Amaral, 2004, p. 2).

Nesta opinião é evidente o preconceito e o desdém que existe no meio da cantoria contra os deficientes físicos, especialmente os cegos. Esse mesmo dono da casa sublinha o respeito que tem por Zé Pretinho quando, para o convidar para a cantoria, "Chamou um dos filhos e disse:/ meu filho, você vá já/ dizer a José Pretinho/ que desculpe eu não ir lá/ e ele como sem falta/ à noite venha cá" (Amaral, 2004, p. 2). Ao contrário, o Cego Aderaldo só colhe desprezo. Ao chegar a Varzinha, "[...] o dono da casa/ me perguntou sem carinho/ cego, você não tem medo/ da fama de Zé Pretinho?” (Amaral, 2004, p. 2). O próprio Zé Pretinho, ao inteirar-se da identidade do seu pretendente adversário, respondeu: " bom amigo é quem avisa/ menino, dizei ao cego/ que vá tirando a camisa/ mande benzer logo o lombo/ que eu vou dar-lhe uma pisa" (Amaral, 2004, p. 3). Isto contrasta com o respeito e o reconhecimento com que o Cego nos apresentou no início da peleja esse mesmo rival. E como se o desdém combinado de adversário e anfitrião não bastasse, o Cego, além de ser forasteiro, é alvo de zombaria geral: "Tudo zombava de mim" (Amaral, 2004, p. 3).

É, portanto, uma peleja entre dois tipos físicos: um com deficiência, e o outro sem. Voltaremos à questão da cor mas, no início, o fator físico da cor ou da raça parecem não contar, já que, apesar da cor negra de Zé, ele leva vantagem, devido ao que podemos chamar de privilégio geográfico. A discriminação entre os dois cantadores continua mesmo nos aspetos proxémicos e cinésicos da ritualização do evento. Enquanto o Cego já estava na casa do anfitrião, em todos aspectos hóspede malquisto, parado e mal informado ("eu não ainda não sabia/ que o tal José Pretinho/ vinha para a cantoria/ às cinco da tarde"), Zé Pretinho, à maneira de grandes conquistadores, "chegou de cavalaria// O preto vinha na frente/ tudo vestido de branco/ seu cavalo encapotado/ com um passo muito franco/ riscaram de uma só vez/ todos no primeiro arranco" (Amaral, 2004, p. 3).

À grande pompa juntam-se o elemento surpresa (a chegada inesperada) e a presença massiva de personalidades da sociedade local, incluindo o "vigário velho/ cura de três freguesias" (Amaral, 2004, p. 4). Todos apoiam o cantador-herói local e menosprezam o solitário Cego, que não janta fausto- 
samente como o Zé Pretinho, nem beneficia de iguais condições de instalação: "Levaram o negro pra sala/ e depois para a cozinha/ lhe ofereceram um jantar/ de doce, queijo e galinha/ para mim veio um café/ com uma magra bolachinha// Depois trouxeram o negro/ e colocaram no salão/ assentada num sofá/ com a viola na mão/ junto a uma escarradeira/ para não cuspir no chão// Então para me sentar/ botaram um pobre caixão/ já velho, desmantelado/ desses que vêm com sabão" (Amaral, 2004, p. 5).

No requinte dos instrumentos de acompanhamento também se nota o desnível de forças, com a vantagem para o mais forte, que "[...] tirou a viola/ dum saco de chita/ e cuja viola estava/ toda enfeitada de fita/ ouvi as moças dizendo:/ grande viola bonita!” (Amaral, 2004, p. 5). O forasteiro desdenhado confessa: "Eu tirei a rabequinha/ dum pobre saco de meia/ um pouco desconfiado/ por estar em terra alheia/ ouvi as moças dizendo/ meu Deus, que rabeca feia" (Amaral, 2004, pp. 5-6). Essas moças, desempenhando um papel semelhante ao do coro no teatro grego, aparecem como portavozes de uma sociedade cruel que chega a ridicularizar o aspecto físico do Cego: "Um disse a Zé Pretinho/ a roupa do cego é suja/ bote três guardas na porta/ para que ele não fuja/ cego feio assim com óculos/ só parece uma coruja" (Amaral, 2004, p. 6). O único apoio que tem o Cego, parece, é o seu guia, que o tenta animar recorrendo à zoomorfização do negro: "o negro parece o cão/ tenha cuidado com ele/ quando entrar em questão" (Amaral, 2004, p. 7).

Na parte verbal do duelo, o cantador anfitrião, que é o primeiro a cantar, ignora a cortesia do adversário, que o elogia e sugere a saudação do "povo" (Amaral, 2004, p. 7), e ataca prontamente a cor e a cegueira do Cego, terminando numa nota de animalização: "P. - Sai, daí, cego amarelo/ cor de couro de toucinho/ um cego da tua forma/ chama-se abusa vizinho/ aonde eu botar os pés/ cego não bota o focinho" (Amaral, 2004, pp. 7-8). O Cego mostra-se humilde e respeitoso, e exige idêntico tratamento civil: "C - Já vi que o seu Pretinho/ é um homem sem ação/ como se maltrata outro/ sem haver altercação?/ Eu pensava que o senhor possuísse educação" (Amaral, 2004, p. 8). Contra os insultos da parte de Pretinho, o Cego continua num tom reconciliador mas também de sarcasmo: "C. - Seu José, o seu cantar/ merece ricos fulgores/ merece ganhar na sala/ rosa e trovas de amores/ mais tarde as moças lhe dão/ bonitas palmas de flores" (Amaral, 2004, p. 8).

Zé Pretinho não atende aos pedidos do colega, que se mostra indignado perante a atitude de quem "[...] maltrata outro/ sem haver alteração" (Amaral, 2004, p. 8), e escarnece impiedosamente do Cego, agravando os insultos com a repetição do termo "cego", imitando o processo que os bran-

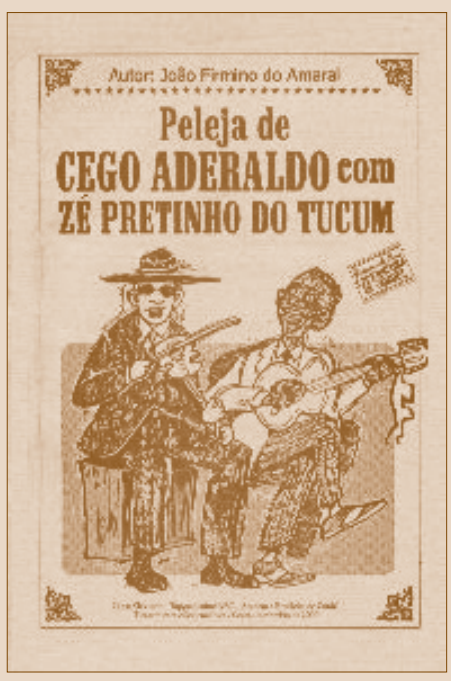


cos arrogantes usam para insultar os negros: "Pr. - Cego, eu creio que tu és/ da raça do sapo sunga/ cego não adora a Deus/ o Deus de cego é calunga/ aonde os homens conversam/ o cego chega e resmunga" (Amaral, 2004, p. 8). A resposta do Cego, já a perder a paciência, já anuncia o que se vai seguir: Ce. - Z' Preto, não me aborreça/ com o teu cantar ruim/ o homem que canta bem/ não trabalha em verso assim/ tirando as falhas que tem/ botando em cima de mim" (Amaral, 2004, p. 9). Zé Pretinho persiste em caluniar o Cego (diz a palavra "cego" quatro vezes na mesma estrofe): "Pr. - Cala-te, cego ruim/ cego aqui não tem figura/ cego quando abre a boca/ é uma mentira pura/ o cego quanto mais mente/ inda mais sustenta a jura" (Amaral, 2004, p. 9). O até então dócil e pacífico cego resolve mudar de tom e rumo, e devolve o ataque racial e de classe social: "Ce. - Este negro foi escravo/ por isso é tão positivo/ quer ser na sala de branco/ exagerado e ativo/ negro da canela seca/ todo ele foi cativo" (Amaral, 2004, p. 9).

A partir daqui, os dois entram num verdadeiro desafio com décimas de insultos, com o Cego em alucinada ofensiva, soltando arrojadas metáforas, enquanto Pretinho reconhece a mudança contra ele e apela para a moderação: "Ce. - Negro, és monturo/ molambo rasgado/ cachimbo apagado/ recanto de muro/ negro sem futuro/ perna de tição/ boca de purrão/ beiço de gamela/ venta de moela/ moleque ladrão// "Pr. - Vejo a cousa ruim/ o cego está danado/ cante moderado/ que não quero assim/ olhe para mim/ que sou verdadeiro/ sou bom companheiro/ canto com maldade/ eu quero a metade/ cego, do dinheiro" (Amaral, 2004, p. 10).

Efetivamente desarmado, Pretinho até chega a conceder abertamente a derrota, e admite ter passado a "subalterno": "Pr. - Cante mais moderno/ perfeito e bonito/ como tenho escrito/ cá no meu caderno/ sou seu subalterno/ embora estranho/ creio que apanho/ e não dou um caldo/ lhe peço, Aderaldo/ reparta a ganho" (Amaral, 2004, p. 11). Contudo, o Cego é irrefreável, e continua desferindo insultos, até os dois chegarem na prova poética denominada "desmancha": "nunca encontrei cantador/ que desmanchasse esse enredo/ é 1 dedo é 1 dado é 1 dia/ é um dia é um dado é um dedo" (Amaral, 2004, p. 13). Zé Pretinho, que já não atinge o nível do Cego, na fase de trava-línguas que se tornaram célebres (e cuja invenção na peleja é atribuída ao autor desta obra, Firmino Teixeira do Amaral) não consegue acompanhar os procedimentos, e pede duas vezes ao colega que repita os versos a serem desmanchados: "Ce. - Amigo José Pretinho/ eu não sei o que será/ de você no fim da luta/ porque vencido já está;/ quem a paca cara compra/ a paca cara pagará// Pr. - Cego, estou apertado/ que só um pinto no ovo/ estás cantando aprumado/ e satisfazendo ao povo/ este seu tema 
de paca/ por favor diga de novo// Ce. - Disse uma e digo dez/ no cantar não tenho pompa/ presentemente não acho/ quem a meu mapa rompa;/ paca cara pagará/ quem a paca cara compra/ Pr. - Cego teu peito é de aço/ foi bom ferreiro que fez/ pensei que o cego não tinha/ no verso tal rapidez/ cego, se não for maçada/ repita a paca outra vez" (Amaral, 2004, p. 14).

O Cego não admite mais repetições dos versos da trava-língua a "este negro capivara" (Amaral, 2004, p. 15), e Pretinho arrisca a desmancha, desastrosamente: "Pr. - Agora, cego me ouça/ cantarei a paca, já/ tema assim é borrego/ no bico dum "carcará"/ quem a cara cara compra/ caca caca cacará" (Amaral, 2004, p. 15). O público é testemunha e juiz, e o apologista resume tudo. Por isso, "Houve um trovão de risadas/ pelo verso de Pretinho/ o capitão Duda disse:/ arreda pra lá, negrinho/ vai descansar seu juízo/ que o cego canta sozinho" (Amaral, 2004, p. 15). Sai vaiado o negro.

Nesta peleja, negro e cego integram a categoria de espécies oprimidas, mas entre os dois existem, para além da rivalidade poética normal entre cantadores, vários tipos de preconceitos capazes de alimentar um desafio. Ao longo da peleja vai ficando evidente é evidente que não é a discriminação contra os negros que está sendo denunciada, mas sim o desprezo dirigido contra os cegos. Na prática quotidiana de discriminação contra os aleijados, a fatalidade da deficiência física torna-se a identidade do indivíduo. Desaparece o nome próprio, e a pessoa é denominada pelo nome da deficiência (neste caso a cegueira). Convém observar que, a este mesmo título, a pele negra é considerada uma deficiência física, sendo os seus portadores também chamados de negro/negra ou preto/preta.

Estruturalmente, a peleja comporta duas partes principais: uma primeira parte narrativa inusitada, mas merecidamente longa (as sete primeiras páginas), que contém os aspectos cénicos da performance, e uma segunda reservada ao próprio duelo verbal. Uma grande parte da peleja foi realizada só nessa fase narrativa de ritualização, e ganha pelo cantador não deficiente. Esta fase corresponde à reencenação das orientações e hierarquias da sociedade real, com os seus valores e preconceitos. Mal começa a poesia verbal dialogada (e duelogada), as dinâmicas são invertidas. Na inversão de situações e papéis, o privilegiado torna-se o rebaixado e vice-versa. Dáse o resgate da imagem e do estatuto do diminuído físico, do cego (e, por extensão, de outros tipos como o coxo), sem com isto querermos afirmar que esta terá sido necessariamente a intenção do autor, que não sabemos se reconstituiu uma peleja histórica ou a criou de raiz. Aliás, segundo Ariano Suassuna, "a peleja entre Aderaldo e Zé Pretinho é da autoria do primeiro" (Júnior, 1986, p. 164), o que vem adensar ainda mais as dúvidas que exis- 
tem em torno desta peleja. De qualquer modo, tudo parece indicar que o autor Firmino Teixeira do Amaral está bem sintonizado com as ideias que evidenciámos. É que uma outra obra da sua autoria, a Peleja do Cego Aderaldo com Jaca Mole Primo de Zé Pretinho (s.d.), é uma reedição, com um protagonista diferente, da peleja entre Zé Pretinho e o Cego Aderaldo. Nesta, Jaca Mole surge para vingar a derrota do primo negro, e, como ele, é arrogante. O Cego mantém a mesma postura paciente e conciliadora, no início, mas é obrigado a defender-se: "A - Eu sou brando no cantar/ Quando encontro educação/ Mas cantor igual você/ Precisa aprender lição/ Come fogo em minha unha/ Apanha, não faz ação" (Amaral, s.d., p. 21). O resultado, como na primeira peleja, é o mesmo (a derrota humilhante do negro): "A - É triste ver-se um cantor/ Chocar-se como galinha/ Só me parece um azar/ Ou por outra é sorte minha/ Me lembro de Zé Pretinho/ Que correu para a cozinha// Aí todos acharam graça/ Deram pró cego a vitória/ Lhe deram muitos presentes/ Em paga da sua glória/ Condecoraram Aderaldo/ Traçando seu nome na história" (Amaral, s.d., p. 32).

Outra observação pertinente, para a qual procuraremos avançar algumas hipóteses na conclusão deste artigo, é o recurso de Zé Pretinho e do seu primo a insultos de ordem racial e classe social, apesar de eles fazerem parte do grupo mais vilipendiado a este respeito. Estas pelejas seguem uma tendência a que voltaremos na conclusão: a vitória cabe ao menos privilegiado dos dois cantadores.

\section{HERANÇA DE GERAÇÕES: FILHO DE CEGO (BRANCO) CONTRA NETO DE NEGRO}

Como se percebe pelo título, a Peleja de Aderaldo filho do cego, com Alexandre o Neto de Zé Pretinho, de João Antônio de Barros (João Antônio de Barros, também conhecido como Jotabarros ou Jota Barros, 1935-2009), pretende ser a recuperação da série que acabamos de apresentar, com uma intercalação de uma e duas gerações, respetivamente. De início, não sabemos se essa cantoria foi motivada pelo desejo de vingança por parte de ambos ou de um dos descendentes do Cego e do Pretinho, ou se foi pura e simplesmente a criação de João A. de Barros. O próprio texto vai fornecer algumas pistas para o levantamento de uma hipótese. O autor desta peleja destaca-se enquanto voz narrativa (eu-narrador) e enquanto participante na cantoria. Em primeiro lugar, João A. de Barros teve que adiar um encon- 
tro que ele próprio ia ter com António Trapiá, porque o anfitrião, o major Pedro Ribeiro, ouvira falar de um evento mais espetacular: "Tem dois cantadores na casa/ Do tenente José Marinho/ O filho do cego Aderaldo/ E o neto de Zé Pretinho" (Barros, s.d., p. 2).

O autor e o seu colega foram ao evento "sem saber que íamos/ Participar do artigo" (Barros, s.d., p. 2), mas, logo após as saudações, "Aderaldo falou pra mim/ Eis aí o tal negrinho/ Que chama-se Alexandre/ É neto de Zé Pretinho/ E já disse por aí/ Que de poeta é padrinho" (Barros, s.d., p. 2). Com esta familiarização com um dos cantadores, fica comprometida a neutralidade das observações do autor, desde já claramente identificado com o filho do cego Aderaldo.

São muitos os paralelos entre esta peleja e a dos antecedentes. Antes de mais, a presença de moças enchendo o orgulho do negro, porque "Já sabem, preto com branco/ Sente-se no maior gozo" (Barros, s.d., p. 3). Como sinal da intenção do autor de reviver a velha peleja, uma loura disse ao Alexandre, "Cuidado pra não lembrar-te/ De teu avô Zé Pretinho" (Barros, s.d., p. 3), mesmo se Alexandre rejeita a sugestão, afirmando a sua individualidade - "Eu me chamo Alexandre" (Barros, s.d., p. 3). A seguir, o autor passa em revista, como na peleja-matriz, o grande número de pessoas notáveis que assistem à cantoria (Barros, s.d., pp. 3-4).

Antes da canja de uns dez minutos do autor com Trapiá, "u’a moça ao preto/ Veio-lhe ofertar um cravo" (Barros, s.d., p. 5), tal como três moças ofereceram três anéis a Pretinho, em sinal de apoio. E, num dos paralelos, embora de forma invertida, Aderaldo adverte o rival forasteiro: "Tome cuidado que não / Está em seu ambiente" (Barros, s.d., p. 6). Durante a troca de insultos, Alexandre, tal como o seu avô, fala desse "amarelo" que "parece/ Com um cara de pamonha", e Aderaldo achava que "Tinha graça eu correr/ De um preto de tua igualha/ Enxerido e abiudo" (Barros, s.d., p. 8). Alexandre vê Aderaldo "parecendo o bicho/ Que ronca e come farelo" (Barros, s.d., p. 9), e este ameaça o "molequinho" que "canta nojento" e que insiste em achar "pente pra seu pixaim" (Barros, s.d., p. 10). Entre a animalização do primeiro e os insultos raciais (pixaim é cabelo de negro), revivemos instâncias da peleja do Cego Aderaldo com Zé Pretinho.

Mas encontramos algumas dificuldades ao chegarmos às provas da desmancha de trava-língua. Primeiro, há mais uma inversão: ao contrário da peleja anterior, quem dá o tema da desmancha é o negro: "E eu vou cantar um lema/ Que é pra tirá-lo do rol/ Qu'eu garanto não cantares/ Aqui por este arrebol/ Pinga a pipa para a prato/ Berra o bode mia o gato/ Quebra

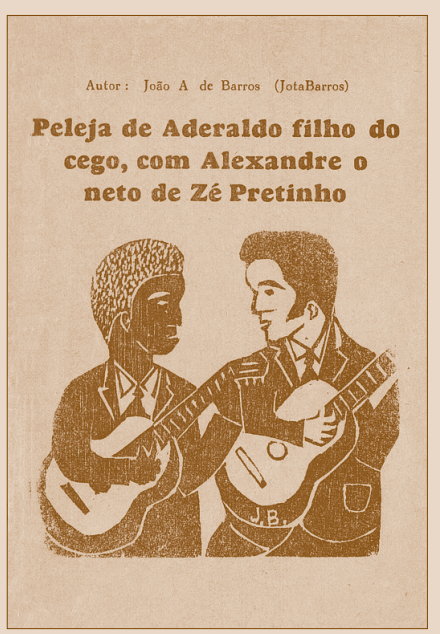


a barra a sai o sol" (Barros, s.d., p. 10). Aderaldo faz a desmancha, sem qualquer problema, e convoca uma zoomorfização ("bodejado"): "O prato apara a pipa/ O gato dá o miado/ Você com seu bodejado/ É quem vai sair da rifa/ O gato come-lhe u'a tripa/ Do seu fígado faz lençol/ Com o calor do farol/ Pinga a pipa para o prato/ Berra o bode mia o gato/ Quebra a barra e sai o sol" (Barros, s.d., p. 11).

É Alexandre, o dono do tema da desmancha, quem erra, especialmente com "Mia o bode berra o gato/ Gira a barra e quebra o sol" (Barros, s.d.: 11). Na velha peleja, quem errou foi o cantador a quem cabia desmanchar a trava-língua. Com esse erro, tal como na primeira peleja, "Acabou-se a cantoria/ Com um trovão de risada/ Pois até eu nessa hora/ Soltei minha gargalhada/ Disseram tira Alexandre/ Que ele não canta nada" (Barros, s.d., p. 11). Mas a cantoria não termina: "Disse o tenente é verdade/ Ele hoje se naufraga/ Agora vou dá um tema/ Pra ver se ele se apaga/ A língua diz e se esconde/ O pé do ouvido é quem paga" (Barros, s.d., p. 12). A posição do tenente não é nada neutra, como se vê. A proposta do tema visa prejudicar Alexandre, o negro. Não surpreende, então, que Aderaldo acerte a glosa, enquanto que Alexandre, logo na primeira tentativa, confunda as rimas: "Ad. - Quem não sabe o que diz/ Só vive desmantelado/ Sujeito a ser apanhado/ E só vive infeliz/ As vezes um homem é infeliz/ Mas a língua lhe naufraga/ Tem vez até que se apaga/ Se esse fizer por onde/ A língua diz e se esconde/ O pé do ouvido é quem paga.// Alex. - Em meu verso improvisado/ Quero dizer no repente/ Que minha volta é por dentro/ Eu não enjeito parada/ Esse meu braço é pesado/ Quem quiser que se esmague/ Lave ensaboe e enxague/ Quem diz é o Alexandre/ A língua diz e se esconde/ O pé do ouvido é quem paga" (Barros, s.d., p. 12).

Desta vez, "a gargalhada/ Zuou mais de meia hora" (Barros, s.d., p. 13), depois da qual o tenente pediu um martelo, enquanto que o eu-narrador optou por "Um martelo malcriado/ Pra jogar o preto fora" (Barros, s.d., p. 13). Aderaldo, tal como fizera o pai, desferiu insultos antecedidos pelo termo "negro" ou derivados, como "Negrinho atrevido/ Metido a cantor" (Barros, s.d., p. 13), "Negro desgraçado/ Tipo Pigmeu" (Barros, s.d., p. 14) e "Negro sem critério/ Cara de jumento/ Sujeito nojento" (Barros, s.d., p. 15). Alexandre, também na linha do avô, cede, mas mostra-se ainda mais apagado, submisso, suplicante, arrependido, reduzido a um estereótipo de negro que conhece o seu lugar: "Cante mais jeitoso/ Sem malcriação/ Eu sou seu irmão/ [...] Deus que me defenda" (Barros, s.d., p. 14); "Favor tenha pena/ Do meu sofrimento/ Eu já não aguento" (Barros, s.d., p. 15), "Meu filho meu bem/ Tenha dó de mim/ Não aguento assim/ [...] Se você quiser/ 
Te beijo os pés" (Barros, s.d., p. 16). Segue-se mais uma gargalhada, desta vez a maior "Que já se ouviu nessa vida" (Barros, s.d., p. 16), porque, como o pai, ele lançou mão de uma "estrofe comprida" de doze pés (Barros, s.d., p. 16). E, como o pai, Alexandre fugiu, com a agravante de ele até "deixou na sala: a viola e desertou" (Barros, s.d., p. 16).

A impressão que se tem, face à inverossimilhança dos paralelos e da estranheza dos erros do perdedor, é de que esta peleja foi concebida e executada para espelhar, quase ponto por ponto, a peleja dos antecedentes dos dois cantadores, mas com uma principal transformação: o estatuto e a fama do cantador negro foram rebaixados e os seus defeitos poéticos exacerbados. Sobressai um aspeto nos insultos de Aderaldo Neto contra Alexandre que valida uma das principais denúncias dos movimentos negros do Brasil: a dos afro-brasileiros serem considerados e tratados como estrangeiros não bem-vindos no país que ajudaram a construir com os maiores sacrifícios (a escravatura). Um dos maiores conflitos sociais do Brasil entra assim agudamente na cantoria. Aderaldo chama o adversário de "pigmeu", "dispatriado", e quer vê-lo repatriado para África ("Abissínia"): "Negro desgraçado/ Tipo Pigmeu/ Veja bem que eu/ Estou costumado/ Ver dispatriado/ Sem lar e sem sina/ Entrar em ruína/ Morrer infeliz/ Deixa meu país/ vais pra Abissínia" (Barros, s.d., p. 14).

Importa agora refletir sobre o papel do autor desta peleja (e das anteriores). Se, como afirmam Olga Santos e Marilena Vianna, "o poeta articula personagens quase sempre imaginários, em diferentes graus de arbitrariedade em relação ao real" (1989, p. 34), até que ponto podemos considerar os dois cantadores mais como a visão e a construção do autor, ou mais como a visão da sociedade mais conservadora? Na peleja anterior (da autoria de Firmino Teixeira do Amaral), como vimos, a arrogância de um grande cantador e o desdém que tanto ele como o público dirigem contra os cegos são os temas em discussão, e o resultado é a vitória do menos privilegiado, o Cego. Deste modo se contribui para a denúncia e a correção de uma injustiça humana e social. Na peleja da seguinte geração, da autoria de João A. de Barros, é difícil identificar esta estrutura, porque nenhum dos jovens cantadores é aleijado. Agora impõe-se a questão da raça, que na peleja matriz não era central: o filho do cego é branco, o neto de Zé Pretinho é negro. Para mais, "Tanto Aderaldo, o filho do Cego, e Alexandre, o neto de Zé Pretinho, são cantadores fictícios criados por João António de Barros" (Almeida, e Sobrinho, 1990, p. 106). Independentemente da opção do autor, não há dúvida de que esta peleja está mais ligada à ótica da tradição escriptocêntrica que promove o fomento da discriminação racial. 


\section{CONCLUSÃO}

Nestas pelejas de oposição entre personagens marcadamente diferentes ganha o mais fraco, o cego. Este, aliás, ganha duplamente, porque, sendo o cantador Aderaldo descendente - não cego - do cego Aderaldo, na Peleja de Aderaldo Filho do Cego com Alexandre o Neto de Zé Pretinho há, de certo modo, uma recuperação da vitória do cego sobre o negro arrogante. Quer isto dizer que, como acontece noutras pelejas que opõem cantadores de géneros, classes sociais e raças diferentes, a análise dos discursos em diálogo revela que a loucura, a diferença, a doidice, a submissão ou a resignação, enfim, todos os índices do absurdo e de inferioridade, marginalização, alienação e autoapagamento, são máscaras que permitem a apresentação de críticas e golpes. Neste caso, quem se considera ser humano normal menospreza e vitupera o aleijado ou deficiente físico. É um mundo regido pela lei da sobrevivência do mais forte. Mas contra esta ordem social e mental erguem-se os mais fracos, que enunciam verdades e sabedorias, demonstram destreza poética e derrubam grandes ícones do sistema oficial e do discurso de poder, e assim conseguem aproximar-se daqueles que se dizem superiores, e à frente deles contrariam e desmontam tabus, preconceitos, complexos e fobias. O Brasil construiu-se, e continua a construir-se, com o contributo de pelejas entre tipos radicalmente diferentes.

\section{REFERENCIAS}

Almeida, Á. A. F. de, e Sobrinho, J. A.s (1990). Dicionário biobibliográfico de poetas populares. 2. ed., amp. e ref. 3 vols. Paraíba: Universidade Federal da Paraíba.

Amaral, F. T. do (2004). Peleja de Cego Aderaldo com Zé Pretinho do Tucum. Fortaleza: Tupynanquim / Academia Brasileira de Literatura de Cordel.

Barros, J. A. de (s.d.). Peleja de Aderaldo Filho do Cego, com Alexandre o Neto de Zé Pretinho. S.l.: s.e.

Júnior, M. D. (1986). “Ciclos temáticos na literatura de cordel”. In: Júnior, M. D., et alii. Literatura Popular em Verso: Estudos (pp. 27-177). Belo Horizonte: Itatiaia. São Paulo: Editora da Universidade de São Paulo. Rio de Janeiro: Fundação Casa de Rui Barbosa.

Nogueira, C. (2004). O Essencial sobre a Literatura de Cordel Portuguesa. Lisboa: Imprensa Nacional - Casa da Moeda.

. (2014). "A literatura de cordel de Manoel Monteiro". Symposium. A Quarterly Journal in Modern Literatures, 68(1), 37-50.

Santos, O., e Vianna, M. (1989). O Negro na Literatura de Cordel. Rio de Janeiro: Casa de Rui Barbosa. 